\title{
POTENCIAL DOS ÓLEOS DE CAFÉ VERDE E DE SOJA NA PRODUÇÃO DE BIODIESEL VIA ROTA ETÍLICA
}

Edu de Paula SCAMILHE ${ }^{1}$

Lucas Smith PIMENTA ${ }^{2}$

Ernandes Benedito PEREIRA ${ }^{3}$

\begin{abstract}
${ }^{1}$ Graduado em Bacharelado em Biotecnologia, Universidade Federal de Alfenas, UNIFAL-MG, Laboratório de Bioprocessos, email: edu_scami@hotmail.com

${ }^{2}$ Universidade Federal de São Carlos, Laboratório de Biotecnologia de Plantas, Programa de Melhoramento Genético da Cana-de-Açúcar, Campus de Araras - Centro de Ciências Agrárias, 13600-970, Araras-SP, Brazil. email: smiith@hotmail.com

${ }^{3}$ Universidade Federal de Alfenas, UNIFAL-MG, Campus Sede, Departamento de Alimentos e Medicamentos, Laboratório de Bioprocessos, Rua Gabriel Monteiro da Silva, 700, Centro, Alfenas, 37130-000, email: ernandes.pereira@unifal-mg.edu.br
\end{abstract}

Recebido em: 18/01/2016 - Aprovado em: 22/03/2016 - Disponibilizado em: 30/07/2016

\begin{abstract}
Resumo:
O biodiesel é hoje um dos principais candidatos para a substituição do combustível obtido a partir dos derivados de petróleo já que estes, durante sua queima, apresentam grande potencial poluidor. Por ser um combustível renovável, biodegradável e com baixo teor de poluição, o biodiesel vem sendo estudado cada vez mais no campo de pesquisa, utilizando-se desde alimentos a óleos vegetais. Sua obtenção consiste na conversão de triglicerídeos a ésteres de ácidos graxos a partir do processo chamado de transesterificação. A transesterificação enzimática é um processo vantajoso por se obter uma melhor pureza do produto e, no final, se consegue reutilizar o biocatalisador. As lipases de Candida antarctica são amplamente utilizadas como biocatalisadores neste tipo de processo por apresentarem características favoráveis a obtenção do produto final (biodiesel). Como a região de Minas Gerais apresenta uma vasta produção de café, selecionou-se esta matéria-prima como principal fonte de obtenção do combustível que, futuramente pode ser usado em veículos próprios.
\end{abstract}

Palavras-chave: biodiesel, óleo de café, óleo de soja, transesterificação e lipases.

\begin{abstract}
:
Today the biodiesel is a leading candidate to replace the fuel obtained from petroleum products as these, during burning, have great potential polluter. Because it is a renewable, biodegradable and low-pollution content, biodiesel has been studied increasingly in the search field, using the vegetable oils from foods. The production is the conversion of triglycerides into fatty acid esters from the transesterification process named. The enzymatic transesterification is a beneficial process for getting better product purity and in the end, if you can reuse the biocatalyst. Lipases from Candida antarctica are widely used as biocatalysts in this type of process for presenting favorable characteristics to obtain the final product (biodiesel). Because the region of Minas Gerais has a vast production of coffee, we selected this material as the main source of obtaining the fuel which can be used in future vehicles themselves.
\end{abstract}

Keywords: biodiesel, coffee oil, soybean oil, transesterification and lipases.

\section{Introdução}

Já faz um tempo que o cenário mundial está voltado para o desenvolvimento de novos combustíveis capazes de suprir a demanda mundial energética. Com o aumento acelerado da população mundial e, conseqüentemente, alto consumo de energia, as principais fontes energéticas (reservas de petróleo) estão se esgotando cada vez mais rápido. Em razão desta situação o biodiesel 
vem sendo uma das principais alternativas para a solução deste irreversível problema.

O biodiesel é um combustível renovável, biodegradável e sua queima é mais limpa que o diesel (MOTHÉ, 2005). Sua constituição é uma mistura de ésteres etílicos ou metílicos extraídos de ácidos graxos, obtidos pela transesterificação de quaisquer triglicerídeos com álcool de cadeia curta (metanol ou etanol). Pode ser obtido a partir de óleos vegetais, gorduras animais ou qualquer outra fonte de ácidos graxos (OSAKI, 2008).

Além disso, o biodiesel apresenta uma série de vantagens técnicas em relação ao diesel mineral: prolonga a vida do motor, apresenta melhor lubricidade, baixo risco de explosão, biodegradável, e, é claro, a baixa emissão de gases poluentes durante sua queima. Entretanto, também apresenta suas desvantagens, possuindo maior viscosidade e alto custo para sua produção (MOTHÉ, 2005). Em virtude da maior quantidade de vantagens financeiras e ambientais é que hoje, pode se substituir diesel por biodiesel.

O Brasil é considerado hoje um dos países com maior potencial para a produção do biodiesel devido suas ótimas condições climáticas e grande área territorial. Entretanto, dois fatores dificultam o progresso do biodiesel no Brasil e no mundo: a redução no preço do petróleo e seu elevado custo de produção. Segundo a Lei 11097/05 imposta pela ANP, o país é obrigado a adicionar $5 \%$ de biodiesel ao diesel até 2013 .

Para que o biodiesel seja aceito, este deve atender a alguns parâmetros de qualidade instituídos nas normas. Parâmetros como viscosidade cinemática, índice de iodo, índice de peróxido, índice de saponificação, densidade relativa e índice de acidez, embora sejam originados do óleo mineral, fornecem resultados bastante esclarecedores quanto à qualidade do biodiesel.

A viscosidade do biodiesel aumenta com o comprimento da cadeia carbônica e com o grau de saturação. Uma alta viscosidade resulta na heterogeneidade na combustão do biodiesel, ocasionando a deposição de resíduos nas partes internas do moto; O número de insaturações, analisado pelo teste do iodo, afeta não só na densidade e viscosidade do biodiesel como também a estabilidade de oxidação do biodiesel; A densidade do biodiesel está diretamente ligada com a estrutura molecular das suas moléculas. Quanto maior o comprimento da cadeia carbônica do éster, maior será a densidade, entretanto, se a quantidade de insaturações for grande, a densidade será menor (LÔBO, 2009).

Basicamente, o biodiesel é obtido a partir de uma reação de transesterificação química ou enzimática. Este processo consiste na conversão de triglicerídeos a ésteres de ácidos graxos e glicerina, através da reação com alcoóis, na presença ou não, de um ácido 
ou de uma base forte ou enzima. Como produtos finais são obtidos os ésteres (biodiesel) e a glicerina (BRANCO, 2007). A transesterificação pelo processo químico é mais simples, rápida e com alto rendimento, entretanto, ao final do processo, o catalisador utilizado permanece misturado com a glicerina e dificulta a sua separação e purificação. Já na produção via enzimática, o biocatalisador pode ser reutilizado e o produto apresenta maior pureza. Também se deve atentar quanto ao tipo de álcool (etanol ou metanol) utilizado no processo. O etanol é o mais adequado por ser independente do petróleo, é menos tóxico e apresenta menor custo financeiro (NASCIMENTO, 2001), entretanto, sua grande desvantagem está no fato de promover uma maior dispersão da glicerina no biodiesel, dificultando assim sua separação (LÔBO, 2009).

Como o estado de Minas Gerais é o maior e melhor produtor de café do Brasil, segundo a Companhia Nacional de Abastecimento - CONAB, a matéria prima para o desenvolvimento do biodiesel neste trabalho será o extrato de óleo de café verde.

Assim, neste trabalho, a produção do biodiesel será conduzida através da via enzimática com utilização da lipase de Candida antarctica como catalisador na reação de alcoólise tendo como substrato o extrato de óleo de café verde adquirido comercialmente.
Para garantir a qualidade do biodiesel é necessário estabelecer padrões de qualidade, objetivando fixar teores limites dos contaminantes que não venham prejudicar a qualidade das emissões da queima, bem como o desempenho, a integridade do motor e a segurança no transporte e manuseio (LÔBO, 2009).

O objetivo desse trabalho foi produzir biodiesel via rota etílica a partir do extrato de óleo de café verde utilizando lipase comercial (Candida antarctica) e imobilizada comparando com o óleo de soja.

\section{Procedimentos experimentais}

Nesse trabalho foi utilizada uma lipase comercial na forma de pó de origem fúngica da empresa Sigma Aldrich. Como suporte foi testado o alginato de sódio de grau de pureza analítico. Quanto ao substrato foi utilizado o extrato de óleo de café verde cedido por uma empresa nacional e óleo de soja adquirido no comércio local.

Como materiais de partida foram utilizados: solventes (acetona, álcool etílico, hexano, éter); sais (fosfato bibásico e monobásico de potássio, periodato de sódio); ácidos (sulfúrico, nítrico, fosfórico); bases (hidróxido de potássio, de sódio); emulsificantes (goma arábica em pó); indicadores (fenolftaleína, azul de bromotimol); entre outros reagentes necessários para as reações enzimáticas (por exemplo, periodato de sódio). 


\section{Caracterização da matéria-prima $e$ do produto formado (biodiesel)}

\section{Determinação do índice de acidez total}

De acordo com MORETTO \& FETT, 1998, o índice de acidez total é definido como o número de miligramas de hidróxido de potássio necessário para neutralizar os ácidos livres de um grama da amostra, o índice de acidez revela o estado de conversão do óleo. Foi pesado $2 \mathrm{~g}$ da amostra em um frasco erlenmeyer de $125 \mathrm{~mL}$. Foram adicionados 25 $\mathrm{mL}$ de solução de éter e álcool (2:1) neutra, seguido de agitação e posterior adição de 2 gotas de fenolftaleína. Em seguida uma titulação com solução de hidróxido de sódio $0,1 \mathrm{~N}$ foi realizada até que a solução se torne rosada. $\mathrm{O}$ resultado foi calculado pela relação de massa em mg de hidróxido de potássio consumidos por grama de amostra analisada.

\section{Índice de peróxido (I.P)}

O índice de peróxidos do óleo de café foi determinado de acordo com o método oficial Cd 8b-90 da AOCS (2004). Para esta determinação, uma massa de aproximadamente $5 \mathrm{~g}$ de amostra foi submetida a uma reação com solução saturada de iodeto de potássio por $1 \mathrm{~min}$. $\mathrm{O}$ excesso de iodeto de potássio foi titulado com tiossulfato de sódio $0,01 \mathrm{~N}$. O resultado foi calculado pela relação entre a quantidade em miliequivalentes de peróxido por $1000 \mathrm{~g}$ de amostra.

\section{Índice de Saponificação (I.S)}

O índice de saponificação da matériaprima foi determinado de acordo com as normas do Instituto Adolfo Lutz (1985). Para esta medida uma amostra de 2,5g foi saponificada com solução alcoólica de hidróxido de potássio $(4 \% \mathrm{~m} / \mathrm{V})$ e titulada com ácido clorídrico $(0,5 \mathrm{~N})$.

\section{Densidade}

As densidades foram medidas em temperatura ambiente $\left(25 \pm 1{ }^{\circ} \mathrm{C}\right)$ e para tal, as amostras foram pesadas em balões volumétricos de $10 \mathrm{~mL}$, previamente aferidos. Após a pesagem a densidade foi determinada utilizando a relação entre massa medida (em balança analítica com quatro casas de precisão) e o volume do balão utilizado (previamente aferido com água bidestilada à temperatura de $25^{\circ} \mathrm{C}$ ). O procedimento de medida para todas as amostras foi realizado em triplicata, tendo sido obtido então um valor de densidade média medida e seu respectivo desvio padrão $(\sigma)$. Paralelamente foi feito uma medição com o picnômetro (BROCK et al, 2008). Os picnômetros foram calibrados com água e posteriormente utilizados na determinação das densidades das amostras de biodiesel. As determinações de densidade foram realizadas com réplica.

\section{Viscosidade}

Para a determinação da viscosidade da amostra extrato do óleo de café, do óleo de 
soja e do biodiesel, foi utilizado um viscosímetro da marca Brookfield (Modelo LVDV-III+). O instrumento foi equipado com cilindros de diâmetros diferentes (spindles), em que é utilizado o cilindro adequado conforme a viscosidade do fluido.

\section{Caracterização da lipase comercial}

Determinação da Atividade Hidrolítica em Função do Tempo.

A atividade enzimática foi determinada pelo método de hidrólise, conforme metodologia modificada por SOARES et al (1999). Os cálculos foram baseados na definição de atividade, onde uma unidade de atividade é definida como a quantidade de enzima que libera $1 \mu$ mol de ácido graxo por minuto de reação, nas condições do ensaio. Para cada análise de atividade, foi realizado um branco utilizando água destilada ao invés da solução enzimática, mantendo todo o resto do procedimento idêntico. As atividades foram expressas em $\mu$ moles/mg.min (U).

\section{Imobilização da lipase AK em suporte POS-} $P V A$

\footnotetext{
A imobilização foi desenvolvida em suporte POS-PVA desenvolvido pelo Laboratório de Biocatálise da EEL-USP. O suporte que, inicialmente, era encontrado na forma de pastilhas foi triturado e peneirado em 42 e 60 mesh, sendo de nosso interesse somente os grânulos retidos na última peneira.
}

Em seguida foi mantido durante $1 \mathrm{~h}$ no shaker em contato com uma solução de epicloridrina 2,5\% (v/v) em tampão fosfato 0,1M e pH 7,5. O suporte foi então filtrado e colocado em contato com hexano e agitado por um período de $2 \mathrm{~h}$. O excesso de hexano foi retirado e ao suporte foi gotejada uma solução de PEG. Após adicionar todo o PEG, toda a solução foi homogeneizada e a enzima adicionada aos poucos. Caso a solução ressecasse, era adicionado hexano. A proporção para este procedimento foi de $0,25 \mathrm{~g}$ enzima/ $1,00 \mathrm{~g}$ suporte/10mL solvente. Após imobilização a enzima foi mantida "overnight" em geladeira, e seca em funil de Büchner por $2 \mathrm{~h}$, seguida de outra etapa de secagem em estufa durante 15 min para que, enfim, pudesse ser utilizada.

\section{Reação de transesterificação enzimática do extrato de óleo de café e de soja em etanol}

Para a produção do biodiesel foi estipulada uma razão molar 1:12 de óleo de café/ álcool em um meio reacional de $30 \mathrm{~g}$. Para isto foi necessário quantificar os ácidos graxos que compunham os óleos em análise. A partir da quantidade de ácidos graxos, selecionaram-se aqueles com maiores concentrações e realizaram-se os cálculos para se determinar a concentração molar de ácidos graxos e concentração molar dos óleos.

A reação de transesterificação ocorreu em reatores de bancada a uma temperatura constante de $45^{\circ} \mathrm{C}$, mantido por um banho 
térmico, e sob agitação mecânica constante, conforme ilustrado na Figura 1. Além disso, a reação de transesterificação ocorreu por um período de $72 \mathrm{~h}$ e as amostras retiradas nos intervalos de tempo de $6,10,12,24,48$ e $72 \mathrm{~h}$ de reação. Em cada intervalo de tempo, foram retiradas amostras do sobrenadante do meio reacional para análise em cromatógrafo a gás. As amostras, antes de passarem pelo cromatógrafo, eram colocadas em contato com Levatite para a retirada de impurezas e glicerol que ainda restavam.

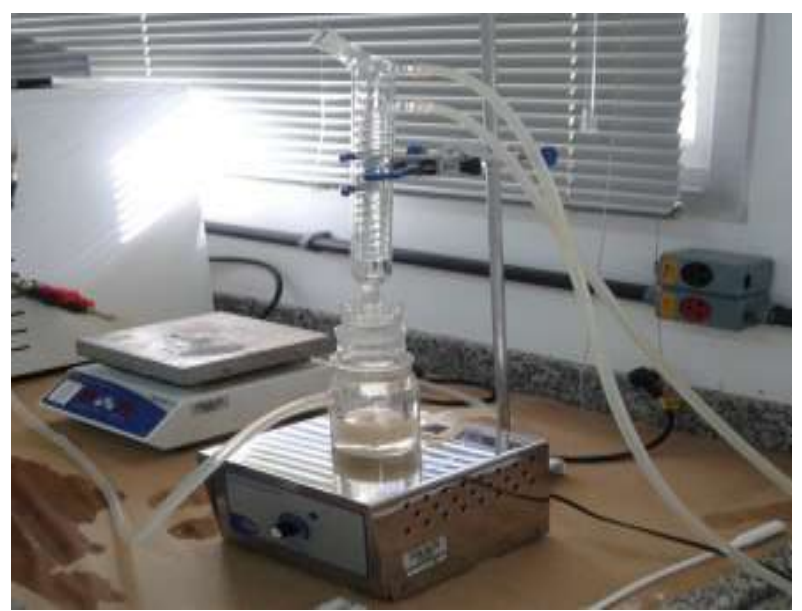

Figura 1. Ilustração do meio reacional para a produção do biodiesel.

\section{Determinação dos ésteres formados e cálculo do rendimento de transesterificação}

Para a análise dos monoésteres de ácidos graxos foi empregado um cromatógrafo de fase gasosa, realizada em outra universidade parceira.

$\mathrm{O}$ rendimento das reações de síntese de biodiesel foi definido como o valor que expressa a massa total obtida de ésteres de etila $\left(M_{t}\right)$ em relação a massa teórica esperada de ésteres de etila $\left(M_{e}\right) \cdot M_{e}$ foi determinada a partir da massa de ácidos graxos presente na massa inicial do extrato dos óleos em análise $\left(\mathrm{M}_{0}\right)$, da massa molecular correspondente a cada ácido $\left(\mathrm{MM}_{\mathrm{a}}\right)$ e do éster correspondente $\left(\mathrm{MM}_{\mathrm{e}}\right)$.

\section{Resultados e Discussão \\ Caracterização da lipase}

A lipase escolhida foi fornecida pela empresa SIGMA ALDRICH e obtida a partir de Candida antarctica (Figura 2). A enzima termoestável é imobilizada em suportes macroporosos de resina acrílica e indicada para reações de síntese de ésteres e amidas.

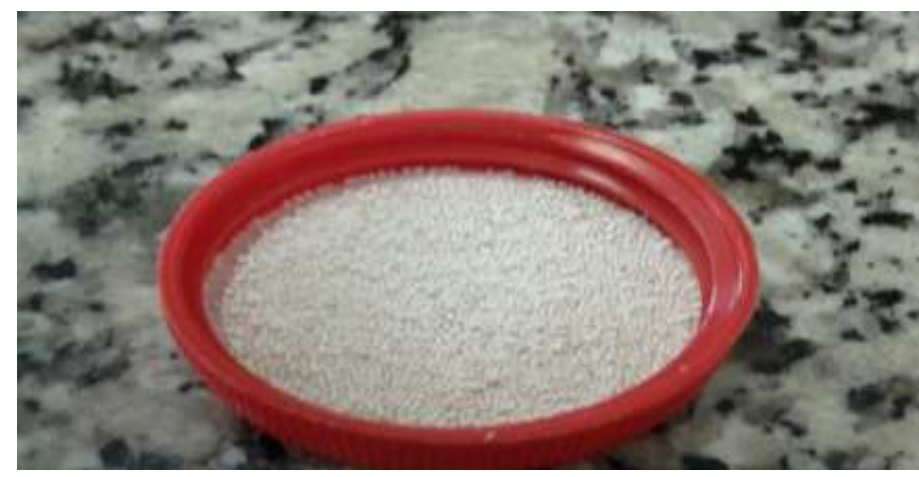

Figura 2. Lipase comercial Candida antarctica

\section{Caracterização do óleo de café e de soja}

\section{Características físico-químicas}

Tabela 1 - Caracterização físico-química do óleo de café e de soja

\begin{tabular}{|c|c|c|}
\hline & $\begin{array}{c}\text { Óleo de } \\
\text { Café }\end{array}$ & $\begin{array}{c}\text { Óleo de } \\
\text { Soja }\end{array}$ \\
\hline Densidade (g/mL) & 0,91 & 0,91 \\
\hline Índice de Acidez & 1,16 & 0,83 \\
\hline $\begin{array}{c}\text { Índice de } \\
\text { Saponificação }\end{array}$ & 209,36 & 186,19 \\
\hline $\begin{array}{c}\text { Índice de } \\
\text { Ind }\end{array}$ & 26,31 & 3,88 \\
\hline
\end{tabular}




\begin{tabular}{|c|c|c|}
\hline Peróxido & & \\
\hline Viscosidade & 32,96 & 32,46 \\
\hline $\begin{array}{l}\text { Viscosidade } \\
\text { Cinemática }\end{array}$ & 36,02 & 35,47 \\
\hline
\end{tabular}

É importante ressaltar que ambos os óleos apresentam parâmetros muito semelhantes quando se deseja sintetizar biodiesel e, como o biodiesel do óleo de soja já existe, a semelhança de ambos os óleos nos evidencia que o óleo de café pode ser uma nova fonte nesta área de biocombustíveis.

A partir dos parâmetros avaliados na Tabela 1, pôde-se notar que o óleo de soja e o óleo de café apresentam um alto potencial para produção de biodiesel já que seus parâmetros físico-químicos analisados não se distanciam dos valores considerados padrões quando se deseja produzir biodiesel. Quando analisamos a viscosidade dos óleos, encontramos um valor considerado alto devido a presença de ácidos graxos de cadeia longa em sua composição, entretanto, este valor não influenciou na produção do biodiesel. Assim como a viscosidade, o índice de peróxido encontrado para o café também se mostrou ser muito alto quando comparado com o óleo de soja, o que poderia influenciar no processo de transesterificação, entretanto, este também não influenciou nos resultados finais.

\section{Composição em ácidos graxos}

Os ácidos graxos em maior quantidade (palmítico, esteárico, oleico, linoleico e linolênico) foram utilizados para a determinação da concentração molar de ácidos graxos $\left(\overline{M M_{a c}}\right)$ e, consequentemente, para a determinação da concentração molar do óleo $\left(\overline{M M_{\text {óleo }}}\right)$ de café a partir da seguinte equação:

$$
\begin{aligned}
& \overline{M M_{a c}}=\frac{\sum p i \phi x M M_{i}}{\sum p i \phi} \mathrm{e} \\
& \overline{M M_{\text {olleo }}}=3 \times \overline{M M_{a c}}+38 \text {, }
\end{aligned}
$$

Onde $\sum p i \%$ é a $\% \mathrm{~m} / \mathrm{m}$ de ácido graxo e $M M_{i}$ a massa molar do ácido graxo.

Tabela 2 - Composição em ácidos graxos do óleo de café.

\begin{tabular}{|c|c|c|c|}
\hline \multicolumn{2}{|c|}{$\begin{array}{c}\text { Ácido Graxo } \\
(\% \mathbf{m} / \mathbf{m})\end{array}$} & $\begin{array}{c}\text { Óleo } \\
\text { de } \\
\text { Café }\end{array}$ & $\begin{array}{c}\text { Óleo } \\
\text { de Soja }\end{array}$ \\
\hline C14:0 & Mirístico & 0,08 & 0,08 \\
\hline C15:0 & Pentadecanóico & 0,04 & 0,05 \\
\hline C16:0 & Palmítico & 10,90 & 10,82 \\
\hline C16:1 & Palmitoléico & 0,08 & 0,09 \\
\hline C17:0 & Margárico & 0,08 & 0,09 \\
\hline C17:1 & Cis-10- & 0,05 & 0,06 \\
\hline C18:0 & Esteárico & 3,73 & 3,69 \\
\hline C18:1 & Oleico & 26,23 & 24,18 \\
\hline $\begin{array}{c}\text { C18:2 } \\
\text { trans }\end{array}$ & t-linoléico & 0,14 & 0,10 \\
\hline C18:2 & Linoleico & 51,00 & 52,72 \\
\hline $\begin{array}{c}\text { C18:3 } \\
\text { trans }\end{array}$ & t-linolênico & 0,44 & 0,30 \\
\hline C18:3 & Linolênico & 5,84 & 6,56 \\
\hline C20:0 & Araquídico & 0,39 & 0,37 \\
\hline C20:1 & Eicosenóico & 0,30 & 0,26 \\
\hline C22:0 & Behênico & 0,51 & 0,46 \\
\hline C24:0 & Lignocérico & 0,19 & 0,17 \\
\hline
\end{tabular}


Os ácidos graxos em menores quantidades foram desconsiderados por apresentarem valores de $\% \mathrm{~m} / \mathrm{m}$ muito baixos logo, sua massa em relação ao todo é desprezível.

Logo, os valores obtidos para $\overline{M M_{a c}} \mathrm{e}$ $\overline{M M_{\text {óleo }}}$ do café foram 278,3 e 873, respectivamente.

\section{Biodiesel Produzido}

Como a razão molar da reação foi de 1:12 óleo/etanol, utilizou-se 18,38g de óleo de café, $11,62 \mathrm{~g}$ de etanol e $3 \mathrm{~g}(10 \%$ do meio reacional) de lipase comercial.

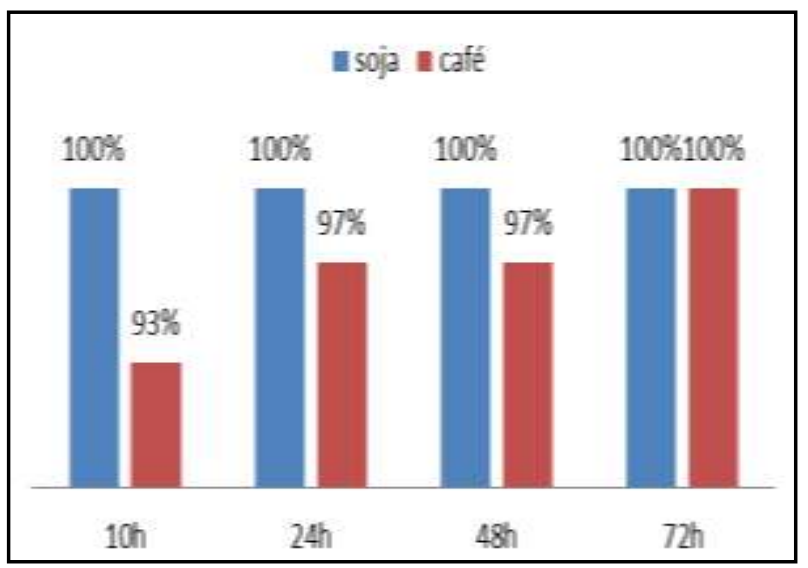

Figura 3. Conversão do óleo de café e óleo de soja a biodiesel em diferentes intervalos de tempo

A partir da Figura 3, podemos notar que a taxa de conversão do óleo de café em biodiesel ocorreu de forma gradativa e de forma satisfatória. Nas 6 primeiras horas de reação o óleo já foi mais de 50\% convertido a ésteres. Com 10 horas de reação a conversão já era quase $100 \%$, entretanto a conversão só se mostrou completa somente após 12 horas de reação. O período de 12 horas de reação é um resultado considerado satisfatório, pois, atualmente, quanto mais rápida a taxa de conversão a biodiesel, melhor é o processo. Como parâmetro de comparação, utilizou-se a produção do biodiesel a partir do óleo de soja, o qual todo o óleo foi convertido em biodiesel em um intervalo inferior a 10 horas de reação.

Logo, o resultado referente ao óleo de café é satisfatório não só pela conversão positiva do óleo, mas também pela rápida obtenção do produto de interesse final.

Uma grande dificuldade encontrada durante o experimento foi que conforme a reação ia ocorrendo, o meio reacional tornava-se mais denso devido a deterioração do suporte da enzima (Figura 4). Essa deterioração é proveniente da agitação mecânica do meio, uma vez que esta é indispensável e relativamente alta.

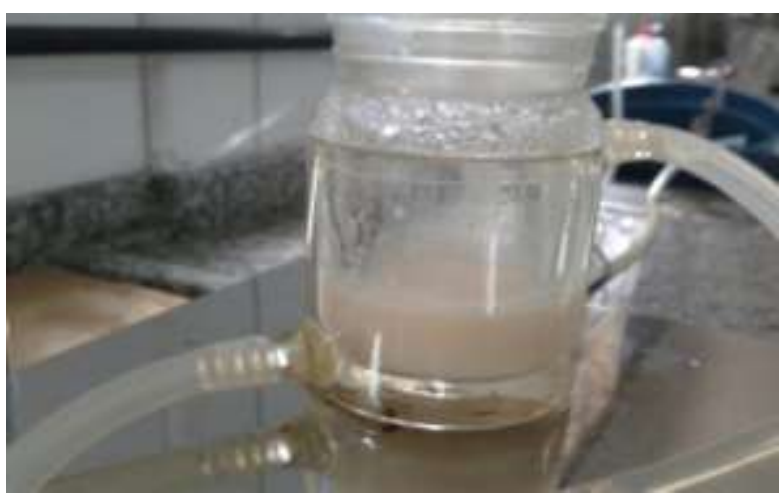

Figura 4. Meio reacional mais denso devido a deteriorização do suporte da enzima.

$\mathrm{Na}$ Figura 5 mostra a diferença entre a enzima/suporte antes de sua utilização no meio reacional e após o sua utilização no mesmo. 


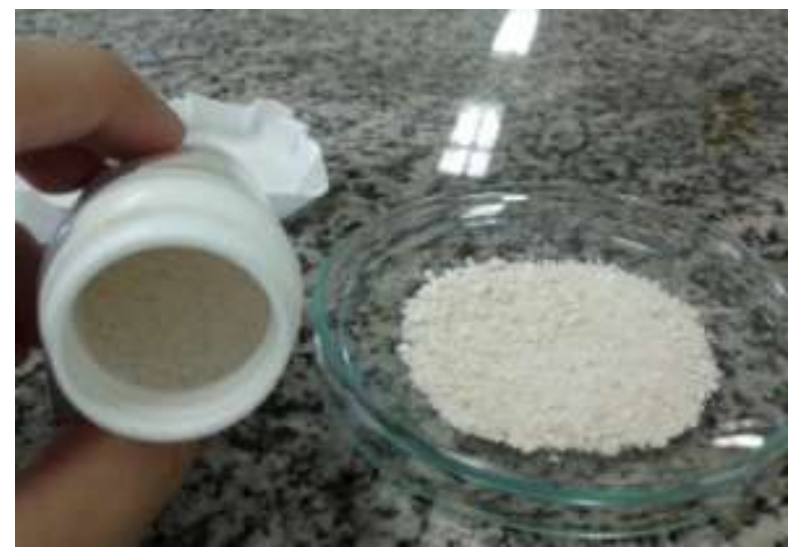

Figura 5. Do lado esquerdoa enzima/suporte antes da sua utilização e do lado direito a enzima utilizada.

\section{Viscosidade do Biodiesel obtido}

Para que um biodiesel possa ser aceito pela ANP (Agencia Nacional do Petróleo, Gás Natural e Biocombustíveis) e ser implantado no mercado, este deve apresentar uma viscosidade cinemática dentro do intervalo de 3,0 a 6,0 cSt. Desta forma, para o biodiesel de café estudado até aqui, conseguiu-se um valor referente a $5,13 \mathrm{cSt}$ o que o torna apto para a implementação no mercado. Já para o biodiesel de soja, o valor obtido foi de 4,81 cSt e, portanto, já é aplicado no mercado de biocombustíveis.

\section{CONCLUSÃO}

$\mathrm{O}$ presente trabalho evidenciou que a via enzimática é capaz de produzir um biodiesel com altos rendimentos e que o óleo de café apresenta um alto potencial na produção de biodiesel. A conversão em biodiesel a partir do óleo de café atingiu os $100 \%$ em um período inferior a $12 \mathrm{~h}$ de reação porém, o que ocorreu antes da total conversão deve ser analisado como conversão satisfatória, já que nesse intervalo a porcentagem de $50 \%$ já tinha sido atingido. Quando próximo das $12 \mathrm{~h}$ de reação, a conversão se mostrou ainda bastante satisfatória com $90 \%$ de conversão. Quando analisado o experimento sob o ponto de vista de escala industrial, onde são avaliados não só a produção, mas também o tempo de conversão, os resultados foram positivos e indicaram que o óleo de café pode se tornar uma fonte oleaginosa com alto rendimento e com elevada capacidade de aplicação na indústria bioenergética, como também é interessante à busca de novas fontes oleaginosas capazes de produzir biodiesel a fim de baratear a produção e comercialização dos mesmos.

\section{AGRADECIMENTOS}

Ao PIBIC/CNPq pela bolsa de Iniciação Científica, à FAPEMIG, a UNIFAL/MG e ao Laboratório de Biocatálise (EEL/USP).

\section{REFERÊNCIAS}

AKOH, C.C.; CHANG, S.W.; LEE, G. C. SHAW, J.F. Enzymatic approach to biodiesel production. Journal of Agricultural and Food Chemistry, 2007, 55, n. 22, 8995.

AMERICAN OIL CHEMISTS' SOCIETY. Official Methods and Recommended Practices of the AOCS. 2004, 5 th Edition AOCS Press.

BROCK, J; NOGUEIRA, M; ZAKRZEVSKI, C; CORAZZA,F; CORAZZA, M; OLIVEIRA, J. Determinação experimental da viscosidade e 
condutividade térmica de óleos vegetais. Ciência e Tecnologia de Alimentos, Campinas, jul.-set.

2008, 28(3),564.

CAMARGOS, R. R. S. Avaliação da viabilidade de se produzir biodiesel através da transesterificação de óleo de grãos de café

defeituosos. Dissertação apresentada ao

Programa de Pós-Graduação em Engenharia

Química da Escola de Engenharia da

Universidade Federal de Minas Gerais, 2005, 105

$\mathrm{p}$,

INSTITUTO ADOLFO LUTZ. Normas

Analíticas do Instituto Adolfo Lutz: métodos químicos e físicos para análise de alimentos. 1985, 1,3a.ed., 533p., São Paulo.

KOHLHEPP, G. Análise da situação da produção de etanol e biodiesel no Brasil. Estudos avançados [online], 2010, 24, n.68, 223.

LÔBO, I.P.; FERREIRA, S.L.C.; CRUZ, R.S. Biodiesel: parâmetros de qualidade e métodos analíticos. Química Nova, 2009, 32, n. 6, 1596.

MORETTO, E., FETT, R. Tecnologia de óleos e gorduras vegetais na indústria de alimentos, Editora UFSC, 1998, 150p.

MOTHÉ, C; CORREIA, D; CASTRO,

B;CAITANO, M. Otimização da produção de biodiesel a partir de óleo de mamona. Revista Analytica, 2005, Ed. 19, Rio de Janeiro.

NASCIMENTO, M. G.; COSTA NETO, P. R.; MAZZUCO, L. M. Biotransformação de óleos e gorduras. Biotecnologia, Ciência \& Desenvolvimento, 2001, ano III.

OSAKI,M; BATALHA, M. Produção de Biodiesel e óleo vegetal no Brasil: Realidade e desafio. Sociedade Brasileira de Economia, Administração e Sociologia Rural. Rio Branco, 2008.

SOARES, C. M. F.; CASTRO, H. F.; ZANIN, G. M.; DE MORAES, F. F. Characterization and utilization of Candida rugosa lipase immobilized on controlled pore silica. Applied Biochemistry and Biotechnology, 1999, 77/79, 745. 